\title{
OS JURISTAS E A POLÍTICA NO BRASIL: PERMANÊNCIAS E REPOSICIONAMENTOS
}

Frederico de Almeida

Universidade de São Paulo (USP), São Paulo, Sp; Instituto de Filosofia e Ciências Humanas da Universidade Estadual de Campinas (IFCH/Unicamp),

Campinas, SP. Brasil.E-mail < fnralmeida@gmail.com >

http://dx.doi.org/10.1590/ 0102-6445213-250/97

O objetivo do presente artigo é discutir, a partir de evidências empíricas sobre as elites jurídicas brasileiras, as relações dos juristas com a política em geral, e com o Estado, em especial, a partir do conceito de campo do poder. Utilizaremos ainda dados específicos sobre a atuação de juristas e de políticos na Reforma do Judiciário de 2004, como referência empírica para se compreender a interação entre atores e saberes especializados em um processo de reforma institucional estatal. À prosopografia de grupos de elites jurídicas brasileiras serão acrescidas análises de trajetórias individuais de juristas, como forma de demonstrar como se dão os trânsitos desses agentes entre o direito e a política ${ }^{1}$.

Seguindo a interpretação weberiana da concentração do poder na sociedade ocidental moderna, Pierre Bourdieu define

1 Os dados e algumas análises expostos neste artigo foram extraídos da pesquisa de Almeida (2010), em que foi feita a prosopografia de membros das cúpulas do Judiciário, do Ministério Público, da Advocacia e do Ministério da Justiça, além da análise de trajetórias individuais de juristas e políticos com atuação no processo político da Reforma do Judiciário de 2004; contudo, para fins deste artigo, optou-se pela apresentação de dados dos membros de algumas cúpulas institucionais apenas e dos atores da Reforma do Judiciário. 
campo de poder como a estrutura resultante da concentração de capitais sociais de diversas origens, realizada especialmente $\mathrm{em}$ torno do e pelo Estado (Bourdieu, 2005, 2007a, 2007b). Nesse sentido, embora, como objeto, campo do poder não se confunda com Estado, o conceito de Bourdieu busca demonstrar como a concentração de poder nas sociedades modernas está diretamente relacionada à gênese do Estado, ainda que as lutas travadas pelos detentores desses recursos de poder não se deem diretamente no interior do Estado - em termos de arenas, regras ou aparatos burocráticos, no sentido dado pelos chamados neoinstitucionalistas (Immergut, 1998; Hall e Taylor, 2003) -, mas sempre em torno do poder do Estado de oficializar divisões de poder e hierarquias social ou economicamente produzidas.

A diferenciação do campo e a concentração do capital especificamente jurídicos coloca o direito e os juristas em uma posição de protagonistas nesse processo (Bourdieu, 2005). A adequação moderna da técnica processual do direito romano 214 às demandas de racionalização do Estado moderno em torno do príncipe, obra cultural dos juristas medievais, é apontada, desde Weber (1999), como condição para o sucesso do processo de burocratização e construção da dominação racional-legal. Nesse processo, em que os juristas produzem o discurso sobre o Estado (especificamente o discurso da soberania do príncipe sobre os interesses particulares e o discurso do Estado de direito), o campo jurídico também ganha autonomia relativa, produzindo uma espécie própria de capital simbólico - o capital jurídico-, consistente numa competência técnica e social de se dizer o direito, que significa, em última análise, o poder de se interpretar e afirmar a visão oficialmente justa ou legítima da ordem social (Bourdieu, 2007a, 2007b).

A diferenciação dos campos de poder, em especial a do campo jurídico em relação às demais esferas de dominação (militar, econômica, cultural), está na base da constituição do poder nos demais campos, mas dá condições, com a progressiva burocratização e divisão do trabalho nas 
sociedades ocidentais avançadas, de posicionar os juristas, e seus interesses específicos, como partícipes dos esquemas de dominação, de forma relativamente imune às lutas travadas em outros domínios, que só adentram ao "mundo do direito" pelos seus próprios termos, ou seja, como um conflito juridicamente classificado e juridicamente solucionável por um processo e uma decisão levados a cabo por juristas. Essa diferenciação de campos de poder, que como se viu está diretamente ligada à construção do Estado burocrático moderno, se deu em tempos diferentes, a depender das circunstâncias específicas dos processos de construção nacional em cada sociedade política, o que pode afetar diferencialmente a posição dos juristas no Estado e na sociedade².

Nesse sentido, a participação dos juristas nos processos de formação tardia de Estados nacionais modernos é evidente na posição direta como elite social e política ocupada por esse grupo social em diversos países. Essa participação se deu por meio dos advogados, em processos políticos liberais, como a Revolução Americana, e pelos juristas de Estado e magistrados, em Estados absolutistas formados em torno de uma forte burocracia, como foi o caso da Prússia, de Portugal e do Brasil (Carvalho, 2007) ${ }^{3}$. No Brasil, esse fenômeno e suas implicações políticas e sociais foi estudado pelas ciências sociais sob o nome de bacharelismo (Faoro, 1958; Oliveira Vianna, 1987; Adorno, 1988; Holanda, 2002).

No Brasil, isso passa a mudar especialmente a partir da Revolução de 1930, quando uma nova divisão do poder entre

\footnotetext{
2 Para uma análise comparativa das profissões jurídicas em relação a diferentes processos de formação do Estado nacional, ver Abel (1982) e Rueschemeyer (1986).

3 Sobre as diferenças entre os advogados (lawyers) da tradição anglo-saxônica e os juristas de Estado da tradição continental, ver Rueschemeyer (1986); sobre as posições de elite dos juristas na América Latina, ver Dezalay e Garth $(2000,2002)$. Sobre a alternância entre magistrados de Estado e advogados liberais na composição da elite política em diferentes momentos da formação do Estado imperial brasileiro, ver Carvalho (2007).
} 
classes dominantes e em torno de um processo de construção institucional colocou o Estado brasileiro como principal agente organizador dos campos de produção cultural (Miceli, 1979). A diferenciação de campos de produção cultural naquele período reposicionou os juristas em relação a outros grupos intelectuais nas relações com a classe dominante, surgidos da diversificação e descentralização geográfica do ensino superior na Primeira República e da formação de novos saberes tecnocráticos para a gestão do Estado (originários das escolas de engenharia, economia e ciências sociais, especialmente) (Santos, 1978; Miceli, 1979). Esse processo de diferenciação e autonomização de campos de poder é, na ótica do campo jurídico, centrado na diferenciação institucional das carreiras jurídicas, o que se dá pela intensificação da burocratização e da racionalização de suas funções em relação ao Estado; esse processo, por sua vez, só vai se definir com as conquistas institucionais e corporativas na Constituição de 1988 (Engelmann, 216 2006a), baseado em projetos políticos de autonomia profissional dos operadores do direito e suas lideranças (Bonelli, 2002).

A profissionalização dos juristas, contudo, não significa que eles se afastaram do campo do poder ou da atividade política. Além dos estudos sobre elites políticas, que demonstram a persistência dos bacharéis em direito na composição de cargos legislativos (Rodrigues, 2002; Braga e Nicolás, 2008), estudos recentes sobre a relação entre juristas e política demonstram sua reinserção em outro patamar, definido justamente por sua expertise profissional, por seu saber especializado, já desde os primeiros anos do regime autoritário de 1930 e nas décadas seguintes (Mattos, 2013; Codato, 2014; Oliveira, 2015).

O presente trabalho busca explorar justamente essa nova inserção dos juristas no campo do poder, construída a partir de sua expertise e de sua autonomia profissional. Num primeiro momento, iremos demonstrar como a profissionalização das carreiras jurídicas representou de fato um afastamento relativo 
dos juristas brasileiros em relação à atividade política em sentido estrito, processo baseado na construção de uma expertise técnica e em instituições de autogoverno dos grupos profissionais. Em seguida, iremos demonstrar como a especialização técnica dos juristas lhes permitiu novas formas de inserção no Estado e na política, que podem conviver com as "velhas" formas de atuação política típicas do bacharelismo político. Uma tipologia dos juristas será desenvolvida e apresentada, como forma de compreender as diferentes trajetórias e inserções possíveis daqueles agentes entre o direito e a política.

Além disso, demonstraremos como a profissionalização dos juristas permite a atuação do próprio grupo profissional e de suas lideranças como atores políticos em interlocução com Estado, a partir do associativismo das profissões jurídicas, e como esse tipo de atividade política, não estatal ou paraestatal, permite a apropriação e a circulação de capital político por parte dos juristas.

Ao final, teceremos algumas conclusões sobre o tema central do artigo, sustentando o argumento de que rearranjos estruturais entre campo político e campo jurídico, e o reposicionamento do campo jurídico em relação ao campo do poder foram viabilizados pelo reposicionamento dos juristas e das transformações em suas estruturas de capitais, sem contudo significar o rompimento definitivo desses campos ou o afastamento completo dos juristas em relação ao Estado e à política.

\section{Diferenciação e autonomia}

A diferenciação de um campo propriamente jurídico, concebido como "lugar de concorrência pelo monopólio do direito de dizer o direito, [...] na qual se defrontam agentes investidos de competência ao mesmo tempo social e técnica" (Bourdieu, 2007a, p. 212) se intensifica com a burocratização do Estado e da sociedade, com a especialização e a profissionalização da divisão do trabalho, com a expansão 
da litigiosidade e da procura pelos tribunais e, mais recentemente, com a internacionalização da economia e das redes de conhecimento especializado ${ }^{4}$.

A evolução dessa progressiva diferenciação do campo jurídico em relação ao campo político pode ser verificada na comparação entre as trajetórias políticas de membros do Supremo Tribunal Federal (STF), agregadas de acordo com o período de sua indicação para a Corte.

Como vemos no Gráfico 1, a proporção de membros do STF com passagens pela política diminuiu progressivamente ao longo do tempo, permanecendo, contudo, em torno de $20 \%$ (quatro) dos ministros indicados no período da redemocratização (1985-2008), com passagens por cargos políticos

\section{Gráfico 1}

Percentual de ministros do STF em cargos legislativos e executivos

(Brasil, 1889 a 2008)

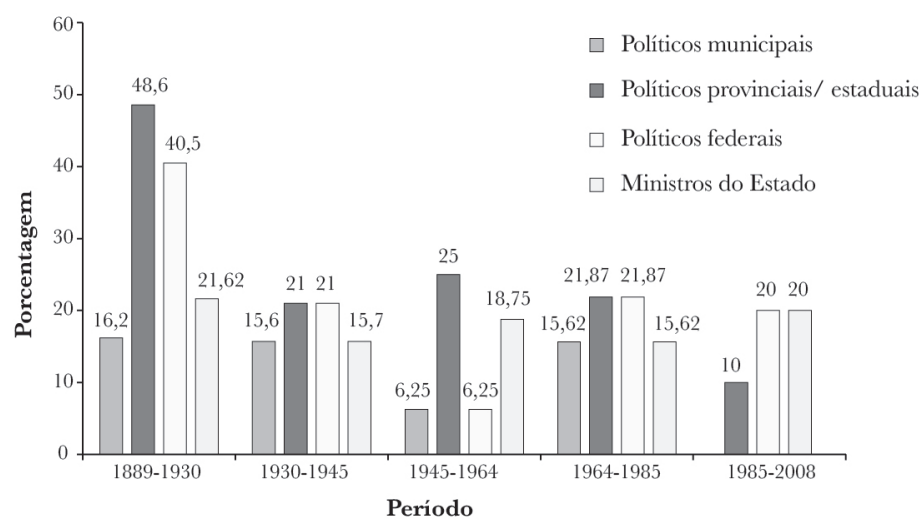

Fonte: Supremo Tribunal Federal (2009).

\footnotetext{
4 Para análises do impacto desses processos sobre as profissões jurídicas, em perspectiva comparada, ver os artigos de Abel (1982), Rueschemeyer (1986) e Dezalay (1991), Dezalay e Trubek (1996), e Dezalay e Garth (2000). Para uma discussão teórica mais detalhada sobre e relação entre profissionalismo e autonomização do campo jurídico, ver Almeida (2014).
} 
federais (deputados, senadores) e/ou de ministro de Estado, e $10 \%$ (dois) dos vinte indicados nesse mesmo período com passagens por cargos políticos estaduais (deputado estadual). Por outro lado, nenhum dos ministros do STF em exercício no ano de 2008 passou por cargos políticos de chefia de Executivo, representação parlamentar ou de ministro do governo federal; se tomarmos os ministros componentes do Superior Tribunal de Justiça (STJ) no ano de 2007, para fins de comparação, apenas um exerceu mandato de vereador municipal (Consultor Jurídico, 2008).

\section{Permanências e reposicionamentos}

Considerando-se, porém, a posição de poder nos campos político e jurídico representada pelo Ministério da Justiça, percebe-se que o capital simbolizado pela passagem por atividades políticas em sentido estrito permanece valorizado, como se vê nas trajetórias políticas e profissionais dos ministros da Justiça dos governos do período da redemocratização. Nesse aspecto, os dados contidos no Quadro 1 devem ser analisados com duas ressalvas.

A primeira delas é a de que o peso real do Ministério da Justiça nas relações de poder do campo político e no campo jurídico é variável e, muitas vezes, depende de conjunturas específicas de lutas em torno de reformas legislativas ou institucionais da justiça; em geral, não é descabido afirmar que em muitos períodos da história republicana, e até em tempos recentes da redemocratização, o papel do órgão abrangia funções diversas, incluindo funções de coordenação institucional e política de governo, atualmente a cargo da Casa Civil da Presidência da República e/ou da Secretaria das Relações Institucionais ${ }^{5}$.

\footnotetext{
5 Um chefe de gabinete do Ministério da Justiça à época da Reforma do Judiciário, entrevistado por mim e Jacqueline Sinhoretto em pesquisa realizada pelo Instituto Brasileiro de Ciências Criminais (Haddad et al., 2006), reproduziu a seguinte expressão, que atribuiu a um ex-ministro da Justiça e do STF: "o Ministério da Justiça trata de
} 


\section{Quadro 1}

Trajetórias políticas e profissionais de ministros da Justiça (Brasil, 1985 a 2010)

\begin{tabular}{|c|c|c|}
\hline Ministro da Justiça & Trajetória política & $\begin{array}{l}\text { Trajetória } \\
\text { profissional }\end{array}$ \\
\hline Fernando Lyra (1985-86) & Deputado estadual, deputado federal & Advogado \\
\hline Paulo Brossard (1986-89) & Deputado federal, senador & Advogado \\
\hline Oscar Dias Correia (1989) & Deputado estadual, deputado federal & Advogado \\
\hline Saulo Ramos (1989-90) & - & Advogado \\
\hline José Bernardo Cabral (1990) & $\begin{array}{l}\text { Deputado estadual, deputado } \\
\text { federal, senador }\end{array}$ & Advogado \\
\hline Jarbas Passarinho (1990-92) & Governador, senador & Militar \\
\hline Célio Borja (1992) & Deputado estadual, deputado federal & Advogado \\
\hline Maurício Corrêa (1992-94) & Senador & Advogado \\
\hline $\begin{array}{c}\text { Alexandre de Paula Dupeyrat } \\
\text { Martins (1994-95) }\end{array}$ & - & Advogado \\
\hline Nelson Jobim (1995-97) & Deputado federal & Advogado \\
\hline Milton Seligman (1997) & $\begin{array}{l}\text { Presidente do PMDB no Distrito } \\
\text { Federal }\end{array}$ & Engenheiro \\
\hline Iris Rezende (1997-98) & $\begin{array}{l}\text { Vereador, prefeito, deputado federal, } \\
\text { governador, senador }\end{array}$ & Advogado \\
\hline Renan Calheiros (1998-99) & $\begin{array}{l}\text { Deputado estadual, deputado } \\
\text { federal, senador }\end{array}$ & $\begin{array}{l}\text { Bacharel em } \\
\text { direito }\end{array}$ \\
\hline José Carlos Dias (1999-2000) & - & Advogado \\
\hline José Gregori (2000-01) & Deputado estadual & Advogado \\
\hline $\begin{array}{l}\text { Aloysio Nunes Ferreira Filho } \\
\qquad(2001-02)\end{array}$ & $\begin{array}{l}\text { Deputado estadual, deputado } \\
\text { federal, vice-governador do Estado } \\
\text { de São Paulo }\end{array}$ & $\begin{array}{l}\text { Procurador } \\
\text { do Estado, } \\
\text { advogado }\end{array}$ \\
\hline Miguel Reale Júnior (2002) & $\begin{array}{l}\text { Suplente de senador, vice-presidente } \\
\text { do PSDB }\end{array}$ & Advogado \\
\hline $\begin{array}{l}\text { Paulo de Tarso Ramos Ribeiro } \\
\text { (2002-03) }\end{array}$ & 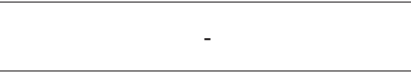 & Advogado \\
\hline $\begin{array}{c}\text { Márcio Thomaz Bastos } \\
(2003-07)\end{array}$ & Vereador & Advogado \\
\hline Tarso Genro (2007-10) & Deputado federal, prefeito & Advogado \\
\hline
\end{tabular}

Fontes: Supremo Tribunal Federal (2009) e dados de 2010 do Senado Federal e Ministério da Justiça, consultados em seus sites. Elaborado pelo autor.

uma enorme variedade de assuntos, que vão da toga à tanga" - referindo-se, obviamente, à competência do Ministério em assuntos diretamente relacionados à administração da justiça (a toga, roupa do juiz), mas também a outras questões de ordem política interna, como no caso da política indigenista (a tanga, roupa do índio), gerida pela Fundação Nacional do Índio (Funai), ligada ao Ministério. 
A segunda ressalva a ser considerada, e que tem a ver com a primeira, é a de que, até mesmo por suas funções muitas vezes mais políticas do que jurídicas, parece compreensível que os titulares do Ministério da Justiça sejam recrutados entre quadros com trajetórias políticas predominantes - daí se entender, por exemplo, a passagem de um engenheiro, de um militar e de um bacharel em direito, sem inserção profissional em carreiras jurídicas, pela chefia do Ministério.

As vinculações dos membros das elites jurídicas com o Estado não se resumem, contudo, à atividade política em sentido estrito, podendo passar também pela ocupação de cargos e funções administrativas de diversos níveis hierárquicos, não diretamente relacionados à atividade judicial. Assim, a análise das trajetórias dos ministros do STF por período de nomeação ao longo da história republicana indica proporções consideráveis de juristas com passagens por cargos administrativos do Estado, sendo a maior dessas proporções $(55 \%)$ verificada entre os membros da Corte indicados no período da redemocratização (ver Gráfico 2).

\section{Gráfico 2}

Percentual de ministros do STF em cargos administrativos (Brasil, 1889 a 2008)

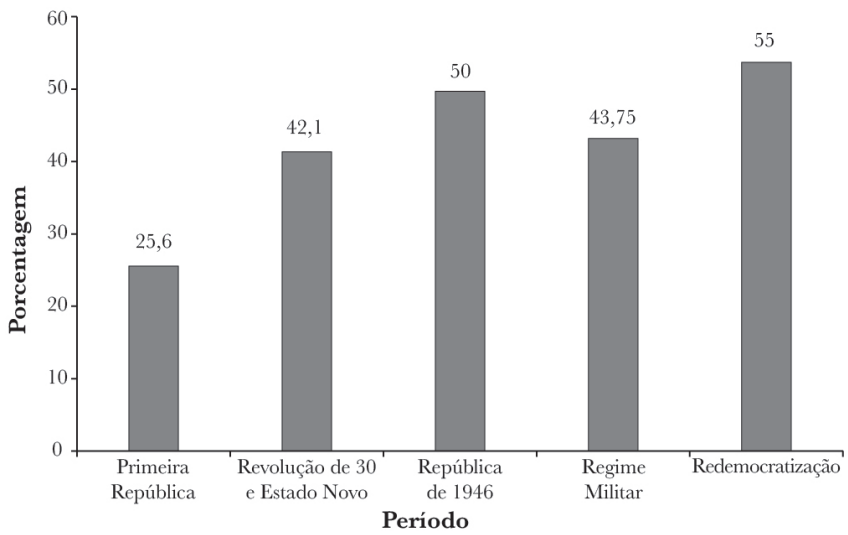

Fonte: Supremo Tribunal Federal (2009). 
A fim de se esclarecer a importância dos dados apresentados no Gráfico 2, para a compreensão das relações entre o campo jurídico e os campos político e burocrático, é preciso estabelecer algumas distinções internas à classificação genérica de "cargos administrativos", utilizadas para a agregação dos dados. Afinal, tais cargos podem incluir desde a chefia de secretarias de governos estaduais e municipais até a função de telegrafista dos Correios, passando pelos postos de direção de órgãos e empresas públicas, ou de assessoramento de ocupantes de burocratas de primeiro escalão.

No caso de funções administrativas de níveis inferior e médio ${ }^{6}$, chama a atenção a recorrência de casos de ministros do STF que foram funcionários dos Correios, especialmente na função de telegrafistas, entre os quais é possível citar os casos de Waldemar Cromwell do Rego Falcão (nomeado ministro em 1941), Antonio Martins Vilas Boas (nomeado ministro em 1957), Eloy José da Rocha 222 (nomeado ministro em 1966) e Raphael de Barros Monteiro (nomeado ministro em 1967). É importante ressaltar que a ocupação de cargos administrativos de níveis inferiores nas hierarquias administrativas do Estado brasileiro não está necessariamente relacionada a uma situação social e familiar menos favorecida - como ilustra o caso do Ministro Barros Monteiro, que faz parte de uma dinastia familiar jurídica de posição destacada no campo jurídi$\mathrm{co}^{7}$. Esse aspecto, ao contrário, reforça a hipótese de que a passagem por cargos públicos tem a função não somente

\footnotetext{
6 Ao classificar as funções de níveis "inferior" e "médio", não estou me referindo necessariamente ao grau de instrução formal exigido para ingresso e exercício do cargo (ensino básico, médio ou superior), mas sim à posição do cargo ou função nas hierarquias administrativas e de prestígio do Estado brasileiro, em geral associadas à classificação em primeiro, segundo, terceiro e quarto escalões.

7 Raphael de Barros Monteiro, ministro do STF nomeado em 1967, era irmão de Washington de Barros Monteiro, desembargador do Tribunal de Justiça do Estado de São Paulo e reconhecido especialista em direito civil, e pai de Raphael de Barros Monteiro, ministro do STJ entre 1989 e 2008.
} 
de permitir maior ascensão social, como também de proporcionar aprendizado prático nas tarefas burocráticas e nos negócios de Estado, mesmo quando o agente já possui capitais sociais e políticos suficientes, produzidos em suas próprias redes de relações. Entre outras funções administrativas de nível médio identificadas na análise das trajetórias de ministros do STF, é possível citar, ainda, as de fiscal (como é o caso de Álvaro Moutinho Ribeiro da Costa, nomeado ministro em 1946, e que anteriormente foi fiscal de bancos da Fazenda Pública) e de funcionário do Banco do Brasil (como é o caso de Ilmar Nascimento Galvão, nomeado ministro em 1991, e que, tendo ingressado nesse banco antes mesmo de sua entrada na faculdade de direito, construiu carreira ascendente no setor bancário público, chegando a diretor e a presidente do Banco do Estado do Acre).

A ocupação de secretarias de governo, chefias de gabinete e direção de órgãos públicos diversos por futuros ministros do STF é uma constante em todo o período analisado, mas é certamente mais recorrente e representativa no período que vai da Primeira República ao Regime Militar. Neste caso, é possível citar os exemplos de José Júlio de Albuquerque Barros (o Barão de Sobral, nomeado ministro do STF em 1891, e que foi diretor da Instrução Pública e secretário de governos provinciais do Ceará), de João Martins de Carvalho Mourão e de José Philadelpho de Barros e Azevedo (nomeados ministros do STF em 1931 e 1942, respectivamente, e que foram ambos membros da Junta Administrativa da Caixa de Amortização), de Edgard Costa (secretário do Interior e da Justiça do Estado do Rio de Janeiro, nomeado ministro do STF em 1945), de Victor Nunes Leal (diretor do serviço de documentação do Ministério da Educação, nomeado ministro do STF em 1960), de Olavo Bilac Pinto (secretário das Finanças do Estado de Minas Gerais, nomeado ministro do Supremo 
em 1970), e de Enrique Ricardo Lewandowski (ministro do Supremo a partir de 2006, tendo sido anteriormente presidente da Empresa Metropolitana de Planejamento da Grande São Paulo).

Da mesma forma, voltando-se aos ministros da Justiça constantes do Quadro 1, é possível dizer que todos, sem exceção, têm alguma passagem pelo Estado, pois, além dos cargos políticos já identificados, mesmo aqueles sem atividade política estrita indicada no quadro possuem passagens anteriores por cargos administrativos de médio e alto escalão, como se vê nos exemplos mais recentes de: José Carlos Dias (secretário de Justiça do Estado de São Paulo), José Gregori (secretário de Participação do Estado de São Paulo e chefe de gabinete dos Ministérios da Reforma Agrária, da Previdência Social e da Fazenda), Aloysio Nunes Ferreira Filho (secretário de Transportes Metropolitanos do Estado de São Paulo e secretário-geral da Presidência da Repúbli224 ca), Miguel Reale Júnior (secretário da Administração e Modernização do Serviço Público e de Segurança Pública do Estado de São Paulo) e Paulo de Tarso Ramos Ribeiro (secretário da Fazenda do Estado do Pará).

A circulação desses agentes, juristas de formação, por diversos cargos de assessoria e execução de governo é emblemática de sua posição como juristas da política, que será mais bem analisada no Diagrama 1 na próxima seção. O mesmo pode ser dito, por exemplo, dos ministros do Tribunal Superior do Trabalho (TST), no ano de 2007, Emmanoel Pereira (que foi oficial de gabinete do governador do Rio Grande do Norte), Ives Gandra Filho (que foi assessor da Casa Civil da Presidência da República) e Vieira de Mello (oficial de gabinete da Secretaria de Segurança Pública de Minas Gerais), bem como dos ministros do STJ, no mesmo ano, Francisco Falcão (oficial de gabinete da Prefeitura de Recife e assessor do governo de Pernambuco), Nilson Naves (assessor do 
Gabinete Civil da Presidência da República) e Peçanha Martins (oficial de gabinete das Secretarias do Interior e da Justiça da Bahia).

Por outro lado, especialmente após a redemocratização, destacam-se trajetórias de ministros do STF com passagens por cargos administrativos porém ligados à atividade judicial, como serviços auxiliares de justiça, assessoria e chefia de gabinete de ministros da Justiça e de membros de tribunais superiores. São exemplos disso as trajetórias de Francisco da Cunha Tavares Melo (nomeado para o Supremo em 1937, tendo sido anteriormente secretário do Tribunal de Justiça do Amazonas), de José Carlos Moreira Alves (chefe de gabinete do ministro da Justiça Alfredo Buzaid e nomeado ministro do STF em 1975), de José Francisco Rezek (ministro do STF nomeado em 1983 e 1992, tendo sido, anteriormente, assessor do então Ministro do Supremo Bilac Pinto), de José Celso de Mello Filho (secretário-geral da Consultoria-Geral da República, ministro do STF a partir de 1989), de José Paulo Sepúlveda Pertence (nomeado para o Supremo em 1989, tendo sido, anteriormente, secretário jurídico do gabinete do então ministro do STF Evandro Lins e Silva), de Ellen Gracie Northfleet (ministra do Supremo a partir de 2000, tendo sido anteriormente assistente técnica do gabinete da Consultoria-Geral do Estado do Rio Grande do Sul) e de Gilmar Ferreira Mendes (assessor técnico do Ministério da Justiça, nomeado ministro do STF em 2002).

Trajetórias semelhantes, de passagem por funções administrativas de apoio à atividade judicial, podem ser identificadas nos currículos, relativos ao ano de 2007, dos ministros do TST Rider de Brito (que foi técnico judiciário do Tribunal Regional do Trabalho), Guilherme Bastos (ex-servidor do extinto Tribunal Federal de Recursos), Lelio Bentes Corrêa (foi assessor judiciário do próprio TST), Pedro Manus (foi servidor do Tribunal Regional do Tra- 
balho da $2^{\text {a }}$ Região), Katia Arruda (ex-oficial de justiça do Tribunal Regional do Trabalho da $7^{\mathrm{a}}$ Região) e Gelson de Azevedo (que também foi servidor do Tribunal Regional do Trabalho da $7^{\text {a }}$ Região), bem como dos ministros do STJ Nancy Andrighi (ex-funcionária do Tribunal de Justiça e do Tribunal Regional Eleitoral do Rio Grande do Sul), Napoleão Maia Filho (foi assessor do presidente do Tribunal de Justiça e do procurador-geral do Ceará) e Nilson Naves (assessor dos ministros do STF Bilac Pinto e Leitão de Abreu). Ao contrário dos casos listados de ministros do STF (em geral, assessores de ministros), algumas trajetórias de ministros do STJ e do TST relacionadas indicam a predominância de ocupações inferiores na hierarquia dos serviços de apoio judiciário (escreventes, oficiais de justiça, serventuários em geral).

De qualquer forma, seja no caso de cargos administrativos de alto escalão, seja no caso das funções administrati226 vas de posição inferior na hierarquia burocrática, é possível afirmar que a vinculação ao Estado produz capital simbólico específico, caracterizado pela construção de redes de relações políticas, pelo aprendizado de rotinas burocráticas e pela criação de disposições vocacionais para o exercício de funções superiores do Estado - mesmo nos casos de agentes já possuidores de estruturas significativas de capitais sociais e políticos. Também é possível afirmar, com base nos dados que demonstram a vinculação de membros da elite jurídica a atividades administrativas, a importância do Estado brasileiro como empregador e mecanismo de incorporação e ascensão social (Miceli, 1979; Werneck Vianna et al., 1997).

\section{Uma tipologia das relações entre juristas e política}

Tendo em vista as trajetórias ilustradas anteriormente e considerando o Diagrama 1 como uma representação esquemática das possíveis combinações de capitais políticos e jurídicos das elites jurídicas, percebemos a persistência de traços 
do bacharelismo, ainda que transformado, na composição do campo jurídico e de suas posições de liderança ${ }^{8}$.

Os bacharéis políticos (A) são aqueles agentes com formação superior jurídica, mas com atividade política predominante. Esse tipo ideal é representado pela quantidade considerável de bacharéis em direito presentes nos quadros legislativos do Estado brasileiro, em todos os níveis federativos (Rodrigues, 2002; Braga e Nicolás, 2008), e que, contudo, têm pouca ou nenhuma atividade profissional jurídica relevante (Sadek e Dantas, 2000). Esse tipo de trajetória evidencia o ainda alto valor simbólico do diploma de bacharel em direito em termos de prestígio social e político, percebido por Sérgio Buarque de Holanda (2002) em sua clássica análise da formação social brasileira, e por Joaquim Falcão (1984) em sua pioneira análise dos advogados e o mercado de trabalho no início dos anos de 1980. Associada a esse valor simbólico do diploma, que independe de seu valor especificamente jurídico (em termos propriamente profissionais), está outra característica da formação superior jurídica, evidenciada pelas trajetórias desses bacharéis polí-

\section{Diagrama 1}

Estruturas de capitais jurídicos e políticos nas trajetórias

de grupos de elites jurídicas

\begin{tabular}{|c|c|c|c|}
\hline \multirow{2}{*}{$\frac{\frac{3}{3}}{\frac{0}{0}}$} & + & $\begin{array}{l}\text { Bacharéis políticos } \\
\text { (A) }\end{array}$ & $\begin{array}{l}\text { Políticos juristas } \\
\text { (B) }\end{array}$ \\
\hline & - & $\begin{array}{l}\text { Juristas da política } \\
\text { (C) }\end{array}$ & $\begin{array}{c}\text { Juristas políticos } \\
\text { (D) }\end{array}$ \\
\hline & & - & + \\
\hline & & \multicolumn{2}{|c|}{ Capital jurídico } \\
\hline
\end{tabular}

Fonte: elaborado pelo autor.

8 Uma apresentação menos desenvolvida desse diagrama e de sua explicação podem ser encontradas em Almeida (2015). 
ticos, que é a baixa taxa de aderência profissional do ensino jurídico, ou seja, a pequena proporção de formados em direito com atuação específica na área (Nunes e Carvalho, 2007).

Apesar da pouca experiência prático-profissional jurídica de grande parte dos bacharéis políticos, sua participação na política das reformas legislativas e judiciais parece ser relevante, demonstrando a importância do título conferido pelo diploma de nível superior. Analisando a participação predominante dos deputados federais que eram também bacharéis em direito na comissão formada na Câmara dos Deputados para a Reforma do Judiciário, Maria Tereza Sadek e Humberto Dantas (2000, p. 110) concluem que

[...] sob a ótica de todos os partidos, a reforma do Judiciário, pelo menos no que se refere às qualificações profissionais do grupo encarregado de propor as emendas, é matéria para "técnicos" no assunto e não para "curiosos".

Os políticos juristas (B) são os que mais de perto reproduzem as trajetórias daqueles bacharéis em direito que participaram diretamente da construção do Estado nacional brasileiro no Império e no início da República, e que têm na antiga magistratura imperial, analisada por Carvalho (2007), seu melhor exemplo. Esse tipo de trajetória é caracterizada por investimentos igualmente relevantes de agentes com trânsitos recorrentes nos campos jurídico e político (especialmente na arena legislativa), e persiste com destaque nas atuais configurações daqueles campos, mesmo diante da progressiva e intensa diferenciação do primeiro em relação ao segundo - o que se dá, como já dito, principalmente pela profissionalização de seus agentes e pelo consequente fechamento de suas fronteiras à entrada de agentes "estrangeiros", representados muito especialmente, no caso do campo jurídico, pelos leigos e políticos profissionais. Exemplos dessas trajetórias, com destaque no processo legislativo da Reforma do Judiciário, são os 
de Hélio Bicudo, Zulaiê Cobra Ribeiro, Nelson Jobim e Michel Temer, figuras que tiveram carreiras jurídicas profissionais de relativo relevo e que, a certa altura da vida, passaram a se dedicar predominantemente à atividade política.

Hélio Bicudo foi membro do Ministério Público do Estado de São Paulo, sendo responsável pela ação do órgão contra o Esquadrão da Morte, formado por policiais paulistas nos anos de 1970 (Souza, 2000); ligado a setores progressistas da Igreja Católica no Brasil, associou-se aos movimentos pela anistia e pelos direitos humanos, consolidando-se como uma liderança da sociedade civil desde a redemocratização; como deputado federal pelo Partido dos Trabalhadores (PT), foi responsável pela apresentação da Proposta de Emenda Constitucional (PEC) nº 96/1992, que deu origem ao processo político da Reforma do Judiciário no Congresso Nacional; sua proposta original, bastante diferente daquela aprovada ao final, tinha caráter muito mais "democratizante", voltada para o acesso à justiça, o desmonte da herança institucional do regime militar e a democratização das carreiras jurídicas - ao contrário do projeto final, de cunho racionalizador e centralizador da administração da justiça (Renault e Bottini, 2005; Sadek e Arantes, 2001).

Zulaiê Cobra Ribeiro, advogada, foi destacada liderança da OAB paulista nos anos de 1980, atuando em comissões da Ordem relacionadas aos direitos das mulheres, às mulheres advogadas e aos direitos da infância e da juventude; como deputada federal pelo Partido da Social-Democracia Brasileira (PSDB), foi uma das relatoras da PEC n ${ }^{\circ}$ 96/1992 no Congresso, durante o período em que o governo Fernando Henrique Cardoso procurou avançar na Reforma do Judiciário; é possível dizer que sua relatoria foi um dos últimos momentos de resistência às propostas centralizadoras que passaram a integrar a PEC da Reforma (Arantes, 2001).

Michel Temer, ex-Procurador do Estado de São Paulo e professor de direito constitucional da Pontifica Univer- 
sidade Católica de São Paulo, foi, como deputado constituinte pelo Partido do Movimento Democrático Brasileiro (PMDB), o principal defensor parlamentar da proposta de institucionalização da advocacia, apresentada pela OAB de São Paulo e que resultou na inclusão do artigo 133 no texto final da Constituição (Almeida, 2005). Na tramitação legislativa da Reforma do Judiciário, e como presidente da Câmara dos Deputados, reinstalou a comissão especial do tema, defendendo a participação privilegiada dos políticos bacharéis na condução do processo (Sadek e Arantes, 2001; Sadek e Dantas, 2000).

Nelson Jobim, advogado, membro de uma tradicional família de proprietários rurais e políticos gaúchos (Grill, 2003), foi titular de uma banca de advocacia conceituada no Rio Grande do Sul. Foi relator, como deputado constituinte pelo PMDB, das propostas de organização da justiça, momento no qual o sistema de justiça e as carreiras jurídicas 230 adquiriram sua feição atual; ainda como deputado, foi o seu trabalho de sistematização de propostas de reforma judicial, na Revisão Constitucional de 1993, que transformou a proposta original de Hélio Bicudo e deu o tom da condução parlamentar da Reforma até a aprovação da Emenda Constitucional no 45/04 (Sadek e Arantes, 2001); já na fase final de aprovação da Reforma, no governo de Luís Inácio Lula da Silva, a posição favorável de Jobim, como presidente do STF, às propostas em discussão, consolidou a aliança entre a liderança executiva da Reforma e o Supremo (Falcão, 2005) e dissipou as resistências ensaiadas por seu antecessor na liderança do tribunal - o Ministro Maurício Corrêa (também um jurista político), que encampou, em grande parte, o discurso corporativo antirreformista da magistratura (Sadek, 2004).

Os juristas da política $(\mathrm{C})$ são os assessores jurídicos de gabinete e os advogados de partido, que prestam serviços técnicos especializados à atividade de políticos profissionais 
e acumulam, dessa forma, quantidades consideráveis de capitais políticos, nas redes de relacionamento com agentes do campo político, ao passo que mantêm sua vinculação estrita ao campo jurídico, pelo exercício de funções típicas e especializadas. Além dos casos já citados no tópico anterior (especialmente entre ministros da Justiça, do STF, do TST e do STJ), sendo exemplos também as trajetórias dos ministros do STF Celso de Mello e Menezes Direito e da processualista Ada Pellegrini Grinover, é nesse espaço de convergência de capitais jurídicos e políticos que se situa, também, a maior parte dos juristas localizados na Secretaria de Reforma do Judiciário do Ministério da Justiça, responsável pela liderança executiva do primeiro ciclo reformista, recrutados entre assessores jurídicos de gabinetes de políticos do Partido dos Trabalhadores e advogados particulares com histórico de representação de interesses de políticos do PT.

Celso de Mello, ex-membro do Ministério Público paulista, foi assessor do advogado e ex-deputado do então Movimento Democrático Brasileiro (atual PMDB) Flávio Bierrenbach por duas vezes, quando este foi consultor jurídico da Secretaria da Cultura e quando foi presidente da Comissão de Constituição e Justiça da Assembleia Legislativa do Estado de São Paulo; também foi assessor e secretário-geral da Consultoria-Geral da República, então liderada pelo jurista Saulo Ramos.

Menezes Direito foi chefe de gabinete do prefeito do Rio de Janeiro e do ministro da Educação, além de presidente da Fundação de Artes do Rio de Janeiro e da Casa da Moeda do Brasil, chegando a ser secretário de Estado da Educação, sempre ligado a gestões políticas do PMDB, entre o fim dos anos de 1970 e início dos anos de 1980. Tanto no caso de Mello quanto no de Menezes Direito, essas relações políticas construídas ao longo de suas trajetórias profissionais foram fundamentais para sua chegada ao STF. 
Ada Pellegrini Grinover, advogada e ex-procuradora do Estado de São Paulo, foi assessora técnica do vice-governador e chefe da Consultoria Jurídica da Secretaria de Justiça do Estado de São Paulo, além de assessora jurídica do senador José Ignácio Ferreira, entre o final da década de 1970 e início da década de 1980.

Sérgio Rabello Tamm Renault, advogado, foi secretário de Reforma Administrativa do governo petista de Luiza Erundina na Prefeitura de São Paulo e sócio do advogado e político do PT José Eduardo Martins Cardoso (que viria a presidir a Comissão da Câmara dos Deputados para a Reforma do Judiciário, e já no governo de Dilma Rousseff, seria ministro da Justiça), tendo governos e políticos petistas em sua carteira de clientes; foi secretário de Reforma do Judiciário no governo Lula. Seu primeiro chefe de gabinete e diretor de Modernização da Administração da Justiça, Pierpaolo Bottini, foi o segundo secretário de Reforma do Judiciário 232 do Ministério da Justiça; advogado, fez sua carreira na assessoria política de mandatos políticos do PT, tendo sido estagiário do advogado e político petista Luís Eduardo Greenhalg (especializado na defesa de presos políticos, no fim do regime militar, e de integrantes do Movimento dos Trabalhadores Rurais Sem Terra, após a redemocratização). Marivaldo Pereira, diretor do Departamento de Política Judiciária da Secretaria de Reforma do Judiciário, foi assessor do político petista José Eduardo Martins Cardozo, citado antes e que foi também ex-vereador na capital paulista e deputado federal.

Por fim, os juristas políticos (D) são aqueles agentes que, assim como os políticos juristas (B), transitam entre os campos político e jurídico com relativo equilíbrio de investimentos, embora mantenham vinculação predominante ao mundo do direito, seja na marca de sua atuação na política (como ministros ou secretários de Justiça, ou mantendo pautas jurídicas em suas atividades parlamentares), seja no maior tempo de vida dedicado às atividades jurídicas. Com 
exemplos anteriores nas trajetórias do Ex-Ministro do STF Evandro Lins e Silva e do Ex-Presidente da OAB José Roberto Batochio, bem como de alguns dos últimos ministros da Justiça citados no Quadro 1, durante a Reforma do Judiciário, os melhores exemplos desse tipo de ator ambivalente são o então Ministro da Justiça Márcio Thomaz Bastos e seu primeiro chefe de gabinete, Sérgio Sérvulo da Cunha.

Evandro Lins e Silva, um dos principais advogados criminalistas do país, foi fundador do Partido Socialista Brasileiro (PSB), em 1947, chefe do Gabinete Civil e ministro das Relações Exteriores do governo do Presidente João Goulart, que o nomeou ministro do STF; ao ser destituído de suas funções pelo AI-6 em 1969, retornou à prática da advocacia e foi membro de diversas composições do Conselho Federal da OAB. José Roberto Batochio, advogado criminalista de renome, foi presidente da Associação dos Advogados de São Paulo (AASP) e da OAB paulista e federal; após passagem pela política, como deputado federal pelo Partido Democrático Trabalhista (PDT), retomou a prática profissional privada. Márcio Thomaz Bastos, ministro da Justiça no período do primeiro ciclo da Reforma do Judiciário (2003-2004), advogado formado pela USP, foi vereador na cidade paulista de Cruzeiro e presidente da OAB de São Paulo e federal na primeira metade dos anos de 1980, engajando a entidade dos advogados nos movimentos pela redemocratização; data dessa época sua relação com Luís Inácio Lula da Silva e com o PT. Tido como um dos principais advogados criminalistas do país, é figura prestigiada no campo jurídico e nos setores políticos mais progressistas. Seu primeiro chefe de gabinete, Sérgio Sérvulo da Cunha, também é figura prestigiada entre advogados e setores políticos e profissionais progressistas, tendo sido presidente do bureau de acompanhamento dos trabalhos constituintes organizados pela OAB de São Paulo junto à Assembleia Nacional Constituinte (1986-1968) e candidato a cargos políticos eletivos pelo PSB. 
Nesse sentido, embora esses tipos ideais não sejam estanques e se verifique a passagem de uma situação típica a outra, dentro de uma mesma trajetória profissional individual, uma explicação que a análise desse perfil das elites jurídicas brasileiras pode sugerir para a Reforma do Judiciário é a de que muito da capacidade do governo federal na interlocução de sucesso com o Congresso e com lideranças do campo político da justiça deveu-se à composição da liderança executiva da Reforma baseada em juristas da política (C) e juristas políticos (D), situados na Secretaria de Reforma do Judiciário do Ministério da Justiça, e à sua aliança com políticos juristas (B) e bacharéis políticos (A), localizados no Parlamento.

Essa explicação - que, de certa forma, ajuda a entender também a mobilização de juristas e suas pautas de interesse durante a Assembleia Nacional Constituinte, quando atores como Nelson Jobim, Maurício Corrêa e Michel Temer, já citados, foram importantes na esfera parlamen234 tar - aponta para outro aspecto da relação entre juristas e a política. Como se vê nas trajetórias utilizadas como exemplo dos tipos ideais de bacharéis ligados à política, há um evidente favorecimento da advocacia e dos advogados nas diferentes formas de interação com o campo político; afinal, a ausência de impedimentos formais à atividade política por parte dos advogados, bem como a construção de sua identidade profissional associada ao mercado e à sociedade (e não ao Estado, como no caso da magistratura e do Ministério Público), possibilitam que a advocacia possa, com maior facilidade, projetar seus membros em atividades de diversos graus de inserção no campo político e no Estado (Almeida, 2014; Engelmann, 2006b) - ou seja, desde a conversão definitiva ou passagens eventuais pela atividade político-partidária, até a especialização na assessoria jurídica da atividade política, caracterizando aquilo que Rueschemeyer (1986) chama de mobilidade lateral da advocacia, em oposição às carreiras de longo prazo dos juristas de Estado. 
No caso dos membros do Ministério Público, a participação em atividade político-partidária e em funções executivas de governo sempre foram temas polêmicos dentro do grupo profissional (Arantes, 2002; Bonelli, 2002), e sua regulamentação recente permite que membros mais antigos do grupo ainda exerçam atividades político-partidárias hoje vedadas a promotores e procuradores. Já no caso da magistratura, as vedações são mais consolidadas (seja como cultura, seja como norma), e, por isso, a interação de seus membros com o campo político depende, em grande parte, de uma conversão definitiva representada pelo afastamento da função - nesse sentido, tome-se como exemplo o deputado federal Flávio Dino, que foi juiz federal e líder associativo da magistratura, com atuação destacada na interlocução com a Secretaria de Reforma do Judiciário e que, após a aprovação da Reforma, deixou a magistratura, elegendo-se para a Câmara dos Deputados e disputando outras eleições para cargos executivos, sempre pelo Partido Comunista do Brasil (PCdoB), sendo eleito governador do Maranhão em 2014.

Nessas situações em que a interação mais próxima com o campo político depende do abandono definitivo da carreira jurídica de Estado, a opção da magistratura e do Ministério Público, em sua interlocução com agentes políticos, acaba passando necessariamente por algum grau de profissionalização da atividade política - seja aquela que executam os seus ex-membros convertidos à atividade político-partidária, seja aquela realizada, a título de lobby ou advocacy, pelos assessores parlamentares e legislativos especialmente contratados pelas instituições e associações profissionais da justiça, a fim de verem representados seus interesses no Poder Legislativo.

Vejamos, a propósito, o depoimento da procuradora da República entrevistada para esta pesquisa:

Eles são bastante atuantes, tanto a ANPR [Associação

Nacional dos Procuradores da República] quanto a Conamp 
[Confederação Nacional dos Membros do Ministério Público]. São bastante atuantes, eles estão todos os dias lá, né? Praticamente todos os dias, e... Não só a Associação, como os assessores parlamentares, também, das instituições. Nós temos um, muito bom, lá, um senhor, que... que conhece a casa, né? Nosso assessor parlamentar, até porque ele é muito, muito, muito antigo lá [...]. Salvo engano, acho que ele foi, ele foi funcionário da própria Câmara [dos Deputados].

A mobilização de representantes profissionais (os assessores legislativos) ou das próprias lideranças do grupo de juristas (em geral, representados por suas associações) depende, segundo o presidente da associação de magistrados, entrevistado para a pesquisa, da facilidade de trânsito da própria liderança profissional pelo campo político - o que, em última análise, depende por sua vez do capital político acumulado, de suas redes de relações e de sua própria 236 trajetória de vida:

Isso aí depende muito do perfil do presidente da associação. Então, só a título de exemplo, eu não tenho assessoria legislativa, mas a Associação da $1^{\mathrm{a}}$ Região, a Ajuferjes [Associação dos Juízes Federais do Rio de Janeiro e Espírito Santo], que era uma associação muito próxima da gente, tal, eles têm um assessor legislativo. O presidente, que é meu amigo, é um cara muito formal. Boa pessoa... mas que é formal no trato com deputado. E eu sei que você tem que mostrar a cara, falar, reunir, tudo... Então que que eu usava? Usava o assessor dele pra trabalhar pra gente. Muitas vezes, pegar assinatura de líder de bancada, eu que ia pegar, junto com o assessor da outra entidade, ou algum deputado que tem uma relação mais próxima com a gente...

De qualquer forma, tanto a procuradora da República e ex-conselheira do Conselho Nacional do Ministério Público 
(CNMP) (sem disposições para a atividade político-partidária) quanto o líder dos magistrados (com experiência prévia em atividade política em sentido estrito, tendo sido assessor legislativo, chefe de gabinete e secretário de governo municipal), entrevistados para esta pesquisa, concordaram com a revisão das regras sobre impedimentos à atividade político-partidária de juízes e membros do Ministério Público. Segundo a procuradora da República entrevistada,

[...] a Constituição deveria ser revista, pra permitir o exercício da atividade político-partidária, tanto para membros do Ministério Público quanto pra magistrados. Porque são as duas únicas carreiras profissionais que não têm representantes [...] tem prejudicado, inclusive, muito a atividade de magistrados e de membros do Ministério Público. Muitas leis são propositadamente mal feitas, né? Eu acho que se tivesse magistrados e mais membros do MP lá, isso não aconteceria...

Já o presidente de associação de juízes entrevistado, embora defenda a participação política de magistrados, vê maiores obstáculos a essa mudança - um de caráter pessoal, ligado à sua própria trajetória, e outro de caráter estrutural, relacionado à ideologia de neutralidade política da magistratura.

Não vejo problema... Acho que a gente teria que repensar um pouco a filiação partidária. Hã... na magistratura, no Ministério Público, podia permitir um pouco mais isso. Hã... eu já vi gente, já vi gente que... que defende um pouco... participação, possibilidade do juiz se candidatar, perder e voltar pra magistratura... Quando o Flavio Dino largou a magistratura pra ser candidato, eu de longe, falei "Meu Deus, coitado, ele vai se esborrachar! Ele não sabe o que que é ser candidato do PCdoB no Maranhão. Que pena, é um sujeito de uma capacidade...”. 
E ele me surpreendeu positivamente. Olha, eu... eu sou favorável à coisa, mas confesso a você que não vou movimentar nenhum, nenhum pauzinho favorável a isso, e porque eu não tenho nenhum interesse em ir pra política partidária. Não tenho... Todo dia eu agradeço ter virado juiz federal. Eu... muito mais... a política institucional, o partido político, não sei... o deputado, tudo... o pessoal não tem a noção do envolvimento, do pique que é, como você estraga sua vida pessoal, e eu não... eu tô aqui trabalhando no meu limite de participação política. Não quero... não pretendo. [...] E, eu acho que a cultura da não participação política da magistratura tá relativamente sedimentada. Não que eu concorde com ela, eu não... [...] Mas eu não, não vou sair no bloco da frente, tendo em vista que o pessoal vai [...] evidentemente achar que eu tô fazendo isso em benefício próprio.

\section{Associativismo e política corporativa}

Percebe-se, portanto, que não é somente quando transitam pelos campos político e burocrático que os juristas acumulam capitais políticos, capazes de posicioná-los nos estratos superiores das hierarquias do campo político da justiça. Os dados de trajetórias de membros das elites jurídicas indicam a importância do associativismo corporativo, mais especificamente do exercício de cargos de liderança corporativa das profissões jurídicas, para a definição das estruturas de poder no campo político da justiça, ao produzirem um tipo específico de capital simbólico, que denomino capital político-associativo.

$\mathrm{O}$ associativismo no campo jurídico, especialmente da magistratura, é tema central da sociologia da administração da justiça (Sousa Santos, 1996), especialmente por conta da importância das associações de magistrados - espanhóis e italianos como casos paradigmáticos - nas redefinições da prática judicial, na interlocução com movimentos sociais 
e na configuração dos movimentos chamados de ativismo judicial, politização da justiça e judicialização da política (Ferrarese, 1984; Faria, 1991; Tate e Vallinder, 1995; Guarnieri e Pederzoli, 1997). Independente do sentido da ação política das associações e lideranças corporativas do campo jurídico (direita/esquerda, progressista/conservador), interessa-me especialmente seu papel na ativação política do campo jurídico (Engelmann, 2006a).

Freidson (1998, p. 123), ao analisar o papel das lideranças profissionais no processo de institucionalização de um grupo profissional, afirma que:

Decisiva para a análise do êxito ou fracasso de uma ocupação na conquista e manutenção de seus abrigos é a análise de sua estratificação e segmentação internas, e o embasamento dessas clivagens na estrutura de sua organização formal e na efetiva capacidade de seus líderes de empreender negociações impositivas no tocante a seu lugar no mercado de trabalho.

Como vemos no Gráfico 3, é crescente a participação, entre ministros do STF, na história republicana, de juristas que exerceram cargos de liderança corporativa dos grupos profissionais do campo, com destaque para o Instituto dos Advogados do Brasil (IAB), entre os indicados durante a Primeira República e os dois primeiros governos de Getúlio Vargas, e para a Ordem dos Advogados do Brasil (OAB), cujos ex-presidentes e conselheiros locais ou nacionais passam a integrar em número crescente aquele tribunal, ao lado de alguns ex-líderes da magistratura nacional, representada pela Associação dos Magistrados Brasileiros (AMB), ou local, representadas por associações estaduais de juízes, com destaque para a Associação Paulista dos Magistrados (Apamagis) e a Associação dos Juízes do Rio Grande do Sul (Ajuris). 


\section{Gráfico 3}

Percentual de ministros do STF em cargos de liderança corporativa

(Brasil, 1889 a 2008)

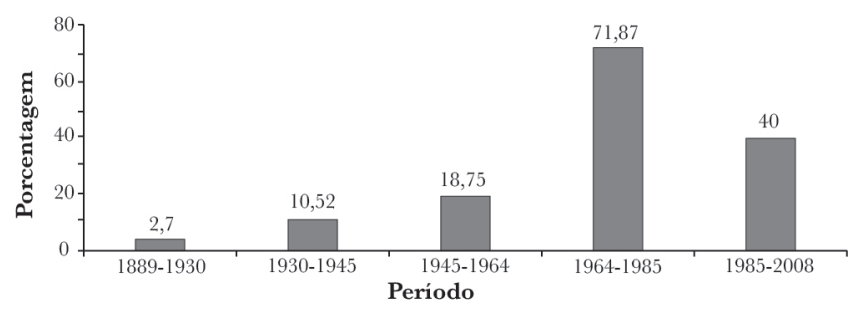

Fonte: Supremo Tribunal Federal (2009).

Não deixa de ser curioso observar a grande proporção de ex-líderes associativos entre os indicados pelos governos militares para a composição do STF, justamente em um período autoritário, cuja oposição, em sua fase final, 240 foi liderada, entre outras organizações, pela OAB - instituição pela qual passou a maior parte dos $23(71,87 \%)$ ministros com experiência de liderança corporativa anterior à nomeação para o Supremo naquele período. Há algumas explicações consistentes para esse aparente paradoxo. A primeira delas é a de que a OAB foi criada por ato do governo federal - mais especificamente, por um único artigo do Decreto $\mathrm{n}^{\circ} 19.408$, de 1930, de Getúlio Vargas, que reorganizou a justiça do Distrito Federal - e, apesar de divergências conceituais acerca da natureza jurídica de sua organização e da construção de sua identidade como parte da sociedade civil, possui caráter paraestatal, com forte vinculação de origem ao Estado; ilustrativo dessa vinculação da $\mathrm{OAB}$ ao Estado, apesar de seu projeto de autogoverno profissional, é o fato de que Levi Carneiro, primeiro presidente da Ordem, foi também um importante quadro político dos dois primeiros governos de Vargas (Miceli, 1979). 
Outro argumento capaz de explicar os dados sobre a participação de lideranças corporativas da advocacia indicadas pelos governos militares para o STF consiste no fato de que somente na fase final do regime militar é que a Ordem se empenhou na oposição à ditadura, sendo sabido seu apoio inicial ao golpe militar de 1964 (Motta, 2006; Rollemberg, 2008). Por fim, mesmo considerando a oposição organizada pela $\mathrm{OAB}$ ao regime militar (e também, anteriormente, ao Estado Novo), é preciso ressaltar a considerável autonomia existente entre os conselhos seccionais e o Conselho Federal da OAB, assim como a autonomia de manifestação política da presidência da $\mathrm{OAB}$ em relação às suas instâncias inferiores (Taylor, 2008). Assim, não é descabido dizer que a oposição da $\mathrm{OAB}$ ao regime militar, além de ter se restringido aos seus últimos anos, pode ter sido obra da presidência de seu Conselho Federal (Motta, 2006), sem necessariamente respaldo ou adesão plena das diversas seccionais espalhadas pelo país.

Percebe-se, portanto, que o capital específico produzido e acumulado no exercício das funções de liderança associativa independe das posições políticas conjunturais adotadas pelas entidades corporativas do campo jurídico em relação ao Estado e ao governo. Analisando a posição institucional do presidente da $\mathrm{OAB}$, a partir de entrevistas com ex-dirigentes da entidade, Marly Silva Motta (2006) destaca a capacidade de acumulação, transmissão e reprodução do capital simbólico da liderança associativa e como essa transmissão, de certa forma, resolve a tensão entre o líder individual e a identidade institucional historicamente determinada.

No fundo, o que está em jogo é a margem de negociação entre a liberdade de agir do indivíduo e os constrangimentos dados pelos padrões definidores de uma determinada 
identidade institucional. As tensões oriundas dessa difícil negociação entre aquilo que o "presidente quer" e o que a "Ordem permite" transparecem com clareza na observação de José Roberto Batochio (1993-95), compartilhada, aliás, por praticamente todos os entrevistados: a cadeira da presidência da $\mathrm{OAB}$, como que por um "fenômeno mágico", se encarregaria de transmitir ao seu ocupante o "legado dos antecedentes" (Motta, 2006, p. 4).

Também na composição do Conselho Nacional de Justiça, em seu primeiro biênio de funcionamento, se percebe a importância do capital político-associativo na estruturação das posições de poder do campo jurídico e do campo político da administração da justiça: doze $(70,58 \%)$ dos dezessete conselheiros que passaram por aquele órgão de controle externo do Judiciário, entre 2005 e 2007, exerceram alguma função de liderança corporativa antes de sua chegada ao Conselho.

A entrevista com o presidente de associação de magistrados, concedida para esta pesquisa, ajuda a entender como a atividade associativa dos grupos profissionais é capaz de produzir capitais políticos específicos, permite a construção de redes de relações internas e externas ao grupo e projeta suas lideranças em posições dominantes do campo político da justiça. Segundo o entrevistado, há três frentes de atuação da associação de magistrados liderada por ele - a social, a sindical e a política:

[...] dentro da primeira, no... que você tá... vamos chamar de parte social, a gente tem eventos, congressos, organiza seminários, não só é aprimoramento do juiz, mas também é um momento de confraternização, de interação entre os colegas... Eu sou um dos juízes que mais conhece todos os colegas hã... na magistratura. Entre cinco que mais conhecem todo mundo, eu estou entre eles com certeza. $\mathrm{E}$ às vezes, com intimidade, talvez eu seja o que mais conheça. [...] 
[...] há um outro lado, que eu, eu diria que é um lado... o pessoal não gosta desse nome, mas é o lado sindical, que são as questões que nós enfrentamos com o tribunal, né? Hã... regulamento pro... pro juiz substituto, processo disciplinar de juiz, isso cresceu bastante; resolução sobre critérios de plantão; pagamento de coisas que não... são devidas e não são pagas, ações judiciais que nós entramos. Então eu diria que esse segundo... é um enfoque...

[...] e o terceiro, que... que de certa forma, eu... que na minha gestão que foi enfatizado, é uma agenda nacional, de ir em Brasília, discutir projetos de interesse da magistratura... então tem... você tem... a... problemas de revisão de subsídios, ampliação... quando eu fui eleito, teve disputa a primeira eleição, né? Então... tinha lá na, na carta programa: ampliação da justiça, revisão dos subsídios, tudo... aí, eu cumpri a carta programa, né? Hã... eu mesmo fiz, então... tinha que... tinha, chamava uma agenda nacional. Então eu chamo isso como uma agenda nacional.

Especialmente naquilo que o entrevistado chama de frente sindical - mas não somente, como se percebe da importância dada às relações construídas em função das atividades sociais, recreativas de sua associação - é que parece estar o foco da mobilização política dos grupos profissionais de juristas em torno de seus interesses. Essa mobilização, que, conforme outros estudos já apontaram (Arantes, 2002; Engelmann, 2006a), contribuiu para a estruturação do campo jurídico e do campo político da justiça, especialmente a partir da Assembleia Nacional Constituinte, ocorre em disputas com as elites do próprio grupo profissional, bem como em lutas com outros grupos de juristas. Segundo se vê no depoimento daquele magistrado, as estratégias adotadas por sua associação nas disputas com a cúpula do próprio tribunal no qual seus associados atuam configuram um campo 
de lutas caracterizadas por tensionamentos e composições constantes, que definem posições diferentes, mas reforçam as conexões internas, as quais dão coesão ao campo e ao grupo profissional:

[...] depende da questão. Tem vezes que você... protocola um ofício. Tem vezes que você avisa. Tem vezes que você ameaça. Tem vezes que você não só ameaça, mas cumpre. [...] aí eu vou lá conversar... aí depois eu protocolo um ofício, ou então vou direto no ofício... eu protocolo o ofício e aviso: "a próxima, nós vamos entrar com uma representação no CNJ.” Então, eu tive... hoje eu já percebi que $[. .$.$] o tribunal tem muito medo de protocolar, da$ gente entrar com uma ação no CNJ. Então eu sempre converso, e falo por dever de lealdade, eu comunico que nós vamos, eu dou prazo. E quando não vai, eu meto mesmo no CNJ, e já entramos com ação judicial também.

244 Quer dizer, é um jogo de... de... negociação, assim... mas tem um lado sindical mesmo, que representa... Aí nós temos veículos, protocolamos o ofício e divulgamos, podemos ir pra imprensa... Tem um repertório de ação que a gente... dependendo da situação, você age de um jeito ou não. Às vezes é uma coisa tranquila, a gente toca... o presidente sabe que tem delegação implícita da diretoria e dos associados, tem vezes que precisa consultar a diretoria, pra ver o tom, e tem vezes que você tem que consultar os associados como um todo. (Entrevista com o presidente de associação de juízes.)

Os dados prosopográficos e as trajetórias individuais analisadas sustentam a hipótese inicial de permanência das relações estruturais entre direito e política, caracterizada 
recentemente por deslocamentos e reposicionamentos dos juristas, em função do surgimento de expertises propriamente políticas e jurídicas, e pela progressiva e relativa autonomização do campo jurídico em relação à política.

A permanência das relações entre juristas e a política é demonstrada pela importância dos capitais políticos na composição das elites jurídicas, e pela existência de perfis de juristas que, de maneiras diversas, conciliam capitais políticos e jurídicos como recursos de poder, acumulados em trajetórias individuais baseadas em diferentes modalidades e intensidades de inserções no campo profissional do direito e na atividade política em sentido estrito. Nesse aspecto, é possível afirmar, em uma primeira análise, que o capital político é mais importante para a configuração das relações de poder no campo jurídico do que o é o capital jurídico para as relações de poder no campo político; trata-se de uma conversão de capitais políticos para emprego nas lutas do campo jurídico.

Fala-se, contudo, em deslocamentos e reposicionamentos dos juristas em relação à política na medida em que, se o "velho" bacharelismo político permanece de maneira residual na composição do campo político, ele é acompanhado de novas formas de inserção dos juristas na vida política. Assim, se a profissionalização e o surgimento de uma expertise propriamente jurídica são marcas da separação gradual do direito em relação à política, são também as condições a partir das quais novas gerações de juristas encontram recursos e caminhos para sua inserção na atividade política, combinando assessoria técnica de mandatários políticos, detenção de cargos públicos relacionados à administração da justiça e mesmo incursões eventuais pela política competitiva. Nesse sentido, teríamos a conversão de capitais jurídicos em recursos de poder utilizados no posicionamento dos juristas nos campos político e burocrático. 
A profissionalização do campo jurídico também permite a constituição e a acumulação do capital político associativo por aqueles juristas que se colocam na condição de lideranças de seus grupos profissionais e assumem a interlocução com o campo político nas questões de interesse corporativo. Esse tipo de relação entre direito e política mostra que a autonomização do campo jurídico - baseada na burocratização das instituições de justiça e na profissionalização de seus operadores - tende a ser apenas relativa, tendo em vista a permanência das conexões das elites jurídicas com o campo político. Mais do que resquício evolutivo tendente a desaparecer em uma formatação ideal de completa autonomia do direito em relação à política (e vice-versa), essa conexão da elite dos juristas com a política parece ser condição da autonomia das bases profissionais, da dominação dessas elites sobre as suas bases e, ao mesmo tempo, o espaço de recrutamento, pelo campo político, dos juristas com possibilidade de conversão de sua expertise profissional 246 ou do prestígio de seu diploma em estratégias de ação política.

\section{Frederico de Almeida}

é professor de Ciência Política no Instituto de Filosofia e Ciências Humanas da Universidade Estadual de Campinas (IFCH-Unicamp), membro do Grupo de Pesquisa em Política e Direito do Centro de Estudos Internacionais e de Política Contemporânea dessa universidade e do conselho científico do Observatório das Elites Políticas e Sociais do Brasil, da Universidade Federal do Paraná (UFPR).

\section{Bibliografia}

ABEL, R. L. 1982. "The underdevelopment of legal professions: a review article on Third World lawyers". American Bar Foundation Research Journal, v. 7, n. 3, pp. 871-93.

ADORNO, S. 1988. Os aprendizes do poder: o bacharelismo liberal na política brasileira. Rio de Janeiro, Paz e Terra.

ALMEIDA, F. N. R. 2005. A advocacia e o acesso à justiça no Estado de São Paulo (1980-2005). Dissertação de mestrado. São Paulo: FFLCH-USP. 
2010. A nobreza togada: as elites jurídicas e a política da justiça no

Brasil. Tese de doutorado. São Paulo: FFLCH-USP.

. 2014. "As elites da justiça: instituições, profissões e poder na política

da justiça brasileira”. Revista de Sociologia e Política, v. 22, n. 52, pp. 77-95.

. 2015. "As elites jurídicas e a democratização da justiça". In:

KASHIURA Jr., C. N.; AKAMINE Jr., O.; MELO, T. (orgs.). Para a

crítica do direito: reflexões sobre teorias e práticas jurídicas. São Paulo:

Expressão Popular.

ARANTES, R. B. 2001. "Jurisdição política constitucional”. In: SADEK, M.

T. (org.). Reforma do Judiciário. São Paulo: Fundação Konrad Adenauer. 2002. Ministério Público e política no Brasil. São Paulo: Educ/Sumaré/

Fapesp.

BONELLI, M. G. 2002. Profissionalismo e política no mundo do direito: as relações dos advogados, desembargadores, procuradores de justiça e delegados de polícia com o Estado. São Carlos, SP: EdUFSCar/Sumaré.

BOURDIEU, P. 2005. "Da casa do rei à razão de Estado: um modelo da gênese do campo burocrático”. In: WACQUANT, L. (org.). O mistério do ministério - Pierre Bourdieu e a política democrática. Rio de Janeiro: Revan.

. 2007a. O poder simbólico. 10. ed. Rio de Janeiro, Bertrand Brasil. 2007b. Razões práticas: sobre a teoria da ação. 8. ed. Campinas, SP:

Papirus.

BRAGA, S. S.; NICOLÁS, M. A. 2008. "Prosopografia a partir da web: avaliando e mensurando as fontes para o estudo das elites parlamentares brasileiras na internet”. Revista de Sociologia e Política, v. 16, n. 30, pp. 107-30.

CARVALHO, J. M. 2007. A construção da ordem: a elite política imperial. Teatro das sombras: a política imperial. 3. ed. Rio de Janeiro: Civilização Brasileira.

CODATO, A. 2014. "Classe política e regime autoritário: os advogados do Estado Novo em São Paulo”. RBCS - Revista Brasileira de Ciências Sociais, v. 29 , n. 84 , pp. 145-63.

CONSULTOR Jurídico. 2008. Anuário da Justiça 2008. São Paulo: FAAP/ Consultor Jurídico.

DEZALAY, Y. 1991. "Territorial battles and tribal disputes". The Modern Law Review, v. 54, n. 6, pp. 792-809.

DEZALAY, Y.; GARTH, B. 2000. "A dolarização do conhecimento técnicoprofissional e do Estado: processos transnacionais e questões de legitimação na transformação do Estado, 1960-2000". RBCS - Revista Brasileira de Ciências Sociais, v. 15, n. 43, pp. 163-76. 
2002. La internacionalización de las luchas por el poder: la competencia entre abogados y economistas por transformar los Estados latinoamericanos. Bogotá: ILSA/Universidad Nacional de Colombia.

DEZALAY, Y.; TRUBEK, D. 1996. "A reestruturação global e o direito a internacionalização dos campos jurídicos e a criação dos espaços transnacionais”. In: FARIA, J. E. (org.). Direito e globalização econômicaimplicações e perspectivas. São Paulo: Malheiros.

ENGELMANN, F. 2006a. Sociologia do campo jurídico: juristas e usos do direito. Porto Alegre: Sergio Antonio Fabris.

2006b. "Internacionalização e ativismo judicial: as causas coletivas". Lua Nova, n. 69, pp. 123-46.

FALCÃO, J. 1984. Os advogados: ensino jurídico e mercado de trabalho. Recife: Massangana. 2005. "Estratégias para a Reforma do Judiciário". In: RENAULT, S.

R. T.; BOTTINI, P. Reforma do Judiciário. São Paulo: Saraiva.

FAORO, R. (1958). Os donos do poder: formação do patronato político brasileiro. Porto Alegre: Globo.

FARIA, J. E. 1991. Justiça e conflito: os juízes em face dos novos movimentos sociais. São Paulo: Revista dos Tribunais.

248 FERRARESE, M. R. 1984. L'istituzione difficile: la magistratura tra professione e sistema politico. Napoli: Edizioni Scientifiche Italiane.

FREIDSON, E. 1998. Renascimento do profissionalismo: teoria, profecia e política. São Paulo: Edusp.

GRILL, I. G. 2003. Parentesco, redes e partidos: as bases das heranças políticas no Rio Grande do Sul. Tese de doutorado. Porto Alegre: IFCH-UFRGS.

GUARNIERI, C.; PEDERZOLI, P. 1997. La democrazia giudiziaria. Bologna: Il Mulino.

HADDAD, E. G. M. et al. 2006. Centros Integrados da Cidadania: desenho e implantação da política pública (2003-2005). São Paulo: IBCCRIM.

HALL, P. A.; TAYLOR, R. C. R. 2003. "As três versões do neoinstitucionalismo”. Lua Nova, n. 58, pp. 193-224.

HOLANDA, S. Buarque de. Raízes do Brasil. 2002. In: SANTIAGO, S. (coord.). Intérpretes do Brasil. v. 3. 2. ed. Rio de Janeiro: Nova Aguilar.

IMMERGUT, E. M. 1998. "The theoretical core of the new institutionalism”. Politics E Society, v. 26, n. 1, pp. 5-34.

MATTOS, M. A. V. L. 2013. Os cruzados da ordem jurídica. A atuação da Ordem dos Advogados do Brasil (OAB), 1945-1964. São Paulo: Alameda. 
MICELI, S. 1979. Intelectuais e classe dirigente no Brasil (1920-1945). São Paulo: Difel.

MOTTA, M. S. 2006. "A Ordem dos Advogados do Brasil: entre a corporação e a instituição". Ciência Hoje, n. 39, pp. 32-7.

NUNES, E.; CARVALHO, M. M. 2007. "Ensino universitário, corporação e profissão: paradoxos e dilemas brasileiros”. Sociologias, v. 9, n. 17, pp. 190-215.

OLIVEIRA, L. B. 2015. A atuação complexa da Ordem dos Advogados do Brasil $(O A B)$ na crise política do governo de Fernando Collor de Mello. Dissertação de mestrado. Campinas, SP: IFCH-Unicamp.

OLIVEIRA VIANA, J. F. 1987. Instituições políticas brasileiras. Belo Horizonte/São Paulo/Niterói: Itatiaia/Edusp/Eduff. 2 v.

RENAULT, S. R. T.; BOTTINI, P. 2005. "Primeiro passo". In: RENAULT, S. R. T.; BOTTINI, P. (coords.). Reforma do Judiciário. São Paulo: Saraiva.

RODRIGUES, L. M. 2002. "Partidos, ideologia e composição social”. RBCS - Revista Brasileira de Ciências Sociais, v. 17, n. 48, pp. 31-47.

ROLLEMBERG, D. 2008. "Memória, opinião e cultura política. A Ordem dos Advogados do Brasil sob a ditadura (1964-1974)”. In: REIS, D. A.; ROLLAND, D. (orgs.). Modernidades alternativas. Rio de Janeiro: Fundação Getúlio Vargas.

RUESCHEMEYER, D. 1986. "Comparing legal professions cross-nationally: from a professions-centered to a State-centered approach". American Bar Foundation Journal, v. 11, n. 3, pp. 415-46.

SADEK, M. T. 2004. "El poder judicial y la magistratura como actores políticos”. In: RODRIGUES, L. M.; SADEK, M. T. A. El Brasil de Lula: diputados y magistrados. Buenos Aires: La Crujía.

SADEK, M. T.; ARANTES, R. B. 2001. "Introdução". In: SADEK, M. T. (org.). Reforma do Judiciário. São Paulo: Fundação Konrad Adenauer.

SADEK, M. T.; DANTAS, H. 2000. "Os bacharéis em direito na reforma do Judiciário: técnicos ou curiosos?”. São Paulo em Perspectiva, v. 14, n. 2, pp. 101-11.

SANTOS, W. G. 1978. Ordem burguesa e liberalismo político. São Paulo: Duas Cidades.

SOUSA SANTOS, B. 1996. Pela mão de Alice: o social e o político na pósmodernidade. 5. ed. Porto: Afrontamento.

SOUZA, P. 2000. Autópsia do medo: vida e morte do delegado Antônio Sérgio Paranhos Fleury. São Paulo: Globo.

SUPREMO TRIBUNAL FEDERAL. Página de internet. Disponível em: $<$ http:/ /www.stf.jus.br>. Acesso em: 6 jun. 2009. 
TATE, N.; VALLINDER, T. 1995. "Judicialization and the future of politics and policy". In: TATE, N.; VALLINDER, T. (eds.). The global expansion of judicial power. New York: New York University Press.

TAYLOR, M. M. 2008. Judging policy: courts and policy reform in democratic Brazil. Stanford: Stanford University Press.

WEBER, M. 1999. Economia e sociedade. v. 2. Brasília: Editora Unb.

WERNECK VIANNA, L. et al. 1997. Corpo e alma da magistratura brasileira. Rio de Janeiro: Revan. 


\section{OS JURISTAS E A POLÍTICA NO BRASIL: PERMANÊNCIAS E REPOSICIONAMENTOS}

\section{FREDERICO DE ALMEIDA}

Resumo: O objetivo deste artigo é discutir, a partir de evidências empíricas sobre as elites jurídicas brasileiras, as relações dos juristas com a política em geral, e com o Estado, em especial, a partir do conceito de campo do poder. Utilizaremos ainda dados específicos sobre a atuação de juristas e de políticos na Reforma do Judiciário de 2004, como referência empírica para se compreender a interação entre atores e saberes especializados em um processo de reforma institucional estatal. À prosopografia de grupos de elites jurídicas brasileiras serão acrescidas análises de trajetórias individuais de juristas, como forma de demonstrar como se dão os trânsitos desses agentes entre o direito e a política. Ao final, se conclui que permanecem as relações estruturais entre direito e política, caracterizada recentemente por deslocamentos e reposicionamentos dos juristas, devido ao surgimento de expertises propriamente políticas e jurídicas, e da progressiva e relativa autonomização do campo jurídico em relação à política.

Palavras-chave: Direito e Política; Juristas; Bacharelismo; Campo Jurídico; Campo do Poder.

\section{LAWYERS AND POLITICS IN BRAZIL: CONTINUITIES AND REPLACEMENTS}

Abstract: This article aims at discussing the relations between lawyers and politics, in general, and between lawyers and the state, in particular. It will do so by analyzing empirical evidences about Brazilian legal elites, and by applying the concept of field of power. It will also be analyzed data about the action of lawyers and politicians during the 2004 Judicial Reform, as an empirical 
reference to understand the interaction between those actors in an institutional political process. The analysis of individual trajectories will complete the prosopography of lawyers in order to show the relations between law and politics. As a conclusion, the article will argue the continuity of the structural relations between law and politics, recently characterized by movements and replacements due to the rising of political and legal expertises, and to the progressive and relative of the legal field.

Keywords: Law and Politics; Lawyers; Legal Elites; Legal Field; Field of Power.

Recebido: 19/12/2014Ａprovado: 04/12/2015 